\title{
EDITORIAL
}

\section{From the new Editor-in-Chief}

\author{
Zheng-Li Shi ${ }^{\bowtie}$
}

Key Laboratory of Special Pathogens and Biosafety, Wuhan Institute of Virology, Chinese Academy of Sciences, Wuhan 430071, China

It is both an honor and pleasure to have been appointed as the Editor-in-Chief of the journal Virologica Sinica from this volume. Professor Xinwen CHEN, who has dedicated to serve the journal as the Editor-in-Chief for 15 years, concluded his term of service in the last volume. I would like to thank Prof. CHEN for his long-standing and extraordinary effort to develop the journal to what it is today. During his term of editorship, the journal has embraced the challenge of English publishing, gained the international recognition, and become one of important academic journals in the field of virology worldwide. And I also want to express my deep gratitude to all our Editorial Board members, reviewers, authors, and readers for their great support and contributions to the journal.

Founded by Professor Zan-Yin GAW, the first issue of Virologica Sinica was published in 1986, originally in the language of Chinese (Figure 1, Gao, 1986). During the Chinese publishing period (1986-2006), Virologica Sinica published 1743 articles for more than 4000 authors, and become a reliable source of quality content and a leading journal on virology in the scientific community of China. In 2007, the journal switched to English publishing for a greater exposure and better information exchange in an international context. Started with few English submissions, striving to build up global reputation, step by step Virologica Sinica grows to a journal indexed by Scopus (2009), PubMed/Medline (2010), and Science Citation Index-Expanded (2015). Till the year 2016, a total of 592 English articles were published for about 2000 authors from 46 countries all over the world (Figure 2).

As to now, Virologica Sinica has accumulated 10 years experience of English publishing. We aim to not only inherit the story, but to also build on its previous success and make it one of the world's influential journals in virology. To achieve this goal, we plan to focus on three major areas: (a) improving the quality of the journal; (b) enhancing the visibility; and (c) increasing the journal's impact.

Content defines a journal. Considering the diversity of rapid progress in virology research, we plan to broaden the journal disciplines and raise attention to the fields, such as emerging viruses, transmission and outbreaks, virus infection and host immunity, viruses of high-level biosafety, interdisciplinary fields of virology-inspired biomedicine and biomaterials. We will invite leaders in both basic and clinic virology all over the world to serve on the Editorial Board to further develop the journal's scientific content and direction. And we would also implement the rigorous peer review process as a value-added step to those potential manuscripts, guarding the quality of our publications.

In recent years, open-access of articles has significantly changed readers' habits, and I will introduce openaccess publishing in Virologica Sinica. Invited expertreview articles and high-quality research articles will be picked out for open-access with no charge to authors. Establishing the best-paper award for work published in Virologica Sinica would be another strategy, and the

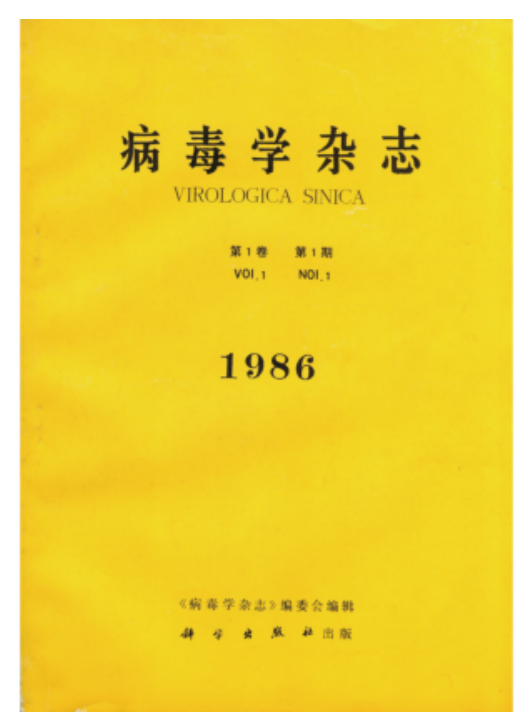

Figure 1. In March of 1986, the inaugural issue of Virologica Sinica was published. 


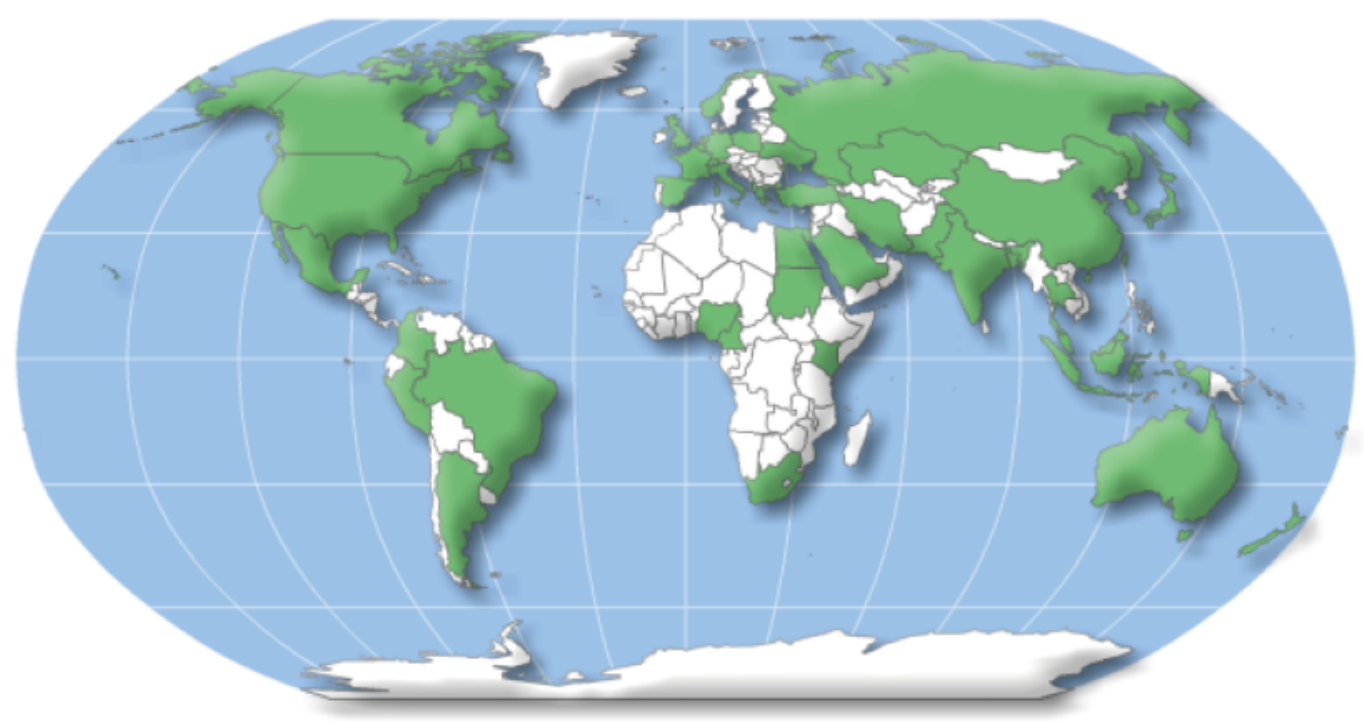

Figure 2. From 2007 to 2016, Virologica Sinica has published 592 articles from 46 different countries, which are marked in green color in the world map.

award will be given every other year since 2017 . We hope to stimulate the best minds to release their best work, and make the journal more attractive for authors and readers.

Organizing special issues will continue to be a norm. The first issue of 2017 is such a special issue with a focus on "Hemorrhagic fever viruses" (HFVs), organized by Prof. Zhihong HU and Prof. Jens KUHN. The reviews and research articles of the issue cover the recent progress on several important HFVs, such as Ebola virus, Dengue virus, Hantavirus, severe fever with thrombocytopenia syndrome virus and Crimean-Congo hemorrhagic fever virus, and we hope the readers would obtain the updated information through this issue. And we also have a call for papers on two special issues at this moment. The first one is on "Herpesviruses and antiviral strategies", edited by Prof. Ke LAN and Prof. Min-Hua LUO. This special issue aims to summarize the recent findings in both laboratory and clinical studies, and can be utilized in the further antiviral therapeutics. The deadline for submission for this special issue is July 31, 2017. Our second special issue will be a focused issue to report the latest findings from a nation-wide surveillance project on "Viruses and their major natural hosts and vectors". Professor Zhiming YUAN, and I myself, will be the Co-Editors of the issue, and we hope to present the community of the findings of both field work and big data mining from this project. The deadline for submission is September 30, 2017. Besides, proposals for themed special issues are always welcome and appreciated.

In conclusion, I would like to put my best effort into being engaged in further improvement of Virologica Sinica, to increase its quality and to better connect, service, and contribute to the community of virology.

\section{$\triangle$ Correspondence:}

Phone: +86-27-87197240, Email: zlshi@wh.iov.cn

ORCID: 0000-0001-8089-163X

Published online: 27 February 2017

\section{REFERENCES}

Gao SY. 1986. Virol Sin, 1: 1-2 